\title{
FUNGSI SEKSUAL WANITA YANG TELAH MENIKAH DI KOTA MAKASSAR
}

\section{The Sexual Function Of Women Has Married In Makassar City}

\author{
Mariany ${ }^{1}$, Nasrudin A.M ${ }^{2}$, Saidah Syamsuddin ${ }^{3}$ \\ ${ }_{1}^{1}$ Program Studi Keperawatan Universitas Sembilanbelas November Kolaka \\ ${ }^{2}$ Bagian Obstetri Gynekologi Fakultas Kedokteran Universitas Hasanuddin \\ ${ }^{3}$ Bagian Sumber Daya Manusia Rumah Sakit Universitas Hasanuddin
}

marianyqdz@gmail.com

\begin{abstract}
Sexual dysfunction is defined as disruption of the sexual response cycle or pain during sexual intercourse. The causes are biological, psychological and interpersonal factors. Biological causes in the form of physical disorders, diseases and side effects of drugs. The purpose of this study was to determine the description of sexual function of married women in Makassar. Subjects in the study were 50 married women who were selected through consecutive sampling techniques. This research is a descriptive study using a cross sectional approach. The results showed the number of women who experienced sexual dysfunction as many as 26 people (52\%). The majority of subjects experiencing sexual dysfunction in the age group 20-30 years (61.5\%), high school education (42.3\%), having a job as a housewife (80.7\%), having two children (53.8\%) \%), using hormonal contraception (61.5\%), and have been married for 3 years (77\%). Suggestions for married women to establish good communication with their husbands include communicating their sexual activities and reducing the impact of stress by doing recreation with family on weekends. For future researchers, in order to conduct research on a larger sample and measure the hormonal levels of research subjects.
\end{abstract}

Keywords : Married women, The sexual function of women

\section{ABSTRAK}

Disfungsi seksual didefinisikan sebagai gangguan siklus respons seksual atau rasa nyeri saat melakukan hubungan seksual. Adapun penyebabnya adalah faktor biologik, psikologik dan interpersonal. Penyebab biologik berupa gangguan fisik, penyakit dan efek samping obat-obatan. Tujuan penelitian ini untuk mengetahui gambaran fungsi seksual wanita yang telah menikah di Kota Makassar. Subjek pada penelitian adalah wanita yang telah menikah berjumlah 50 orang yang dipilih melalui teknik consecutive sampling. Penelitian ini adalah penelitian deskriptif menggunakan pendekatan cross sectional. Hasil penelitian menunjukkan jumlah wanita yang mengalami disfungsi seksual sebanyak 26 orang (52\%). Subjek yang mengalami disfungsi seksual mayoritas pada kelompok umur 20-30 tahun $(61,5 \%)$, pendidikan SMA $(42,3 \%)$, memiliki pekerjaan sebagai ibu rumah tangga $(80,7 \%)$, memiliki anak 2 orang $(53,8 \%)$, menggunakan kontrasepsi hormonal $(61,5 \%)$, dan telah menikah selama 3 tahun $(77 \%)$. Saran bagi wanita yang telah menikah agar menjalin komunikasi yang baik dengan suami termasuk mengkomunikasikan aktifitas seksual mereka dan mengurangi dampak dari stres dengan melakukan rekreasi bersama keluarga diakhir pekan. Bagi peneliti selanjutnya, agar melakukan penelitian pada sampel yang lebih besar serta mengukur kadar hormonal subjek penelitian.

Kata kunci : Fungsi seksual wanita, Wanita yang telah menikah

\section{PENDAHULUAN}

Disfungsi seksual menjadi masalah yang penting bagi setiap orang (Rizvi S.J et al., 2011). Masalah hubungan intim diantara suami istri salah satu hal yang dapat memicu konflik dalam rumah tangga (Maulana, 2012). Disfungsi seksual didefinisikan sebagai gangguan siklus respons seksual atau rasa nyeri saat melakukan hubungan seksual. Adapun penyebabnya adalah faktor biologik, psikologik dan interpersonal. Penyebab biologik berupa gangguan fisik, penyakit dan efek samping obat-obatan (Sadock,
2014). Diabetes, penyakit jantung, gangguan saluran kemih, penyakit kronis, efek samping obat depresi dan kecemasan juga menjadi faktor risiko disfungsi seksual pada pria dan wanita. Disamping itu berbagai faktor sosial dan kultural lain juga berhubungan dengan disfungsi seksual yang terjadi (McCabe et al., 2016).

Perkembangan psikoseksual, sikap psikologis terhadap seksualitas, dan sikap terhadap pasangan seksual secara langsung mempengaruhi fisiologi respons seksual seseorang. Terdapat empat fase yang terjadi pada siklus respons fisiologis seksual yaitu fase hasrat, fase gairah, fase

Vol. XIV No. 2, Desember 2019 
orgasme, dan fase resolusi. Beberapa bentuk disfungsi seksual pada wanita yaitu gangguan hasrat seksual, gangguan perangsangan seksual, gangguan orgasme, gangguan nyeri seksual, disfungsi seksual akibat keadaan medis umum, disfungsi seksual yang diinduksi zat, dan disfungsi seksual yang tidak tergolongkan (Sadock, 2014). Therapy menggunakan obat saja tidak menyelesaikan disfungsi seksual pada wanita, tetapi dibutuhkan penanganan yang multi sektor (Weinberger et al., 2018).

Prevalensi disfungsi seksual pada wanita di daratan China diperkirakan $29.7 \%$ yang terjadi diberbagai domain (Zhang, 2017). Penelitian yang dilakukan terhadap 172 responden di kecamatan Kedaton dan Pagelaran, Lampung didapatkan 87 responden $(50.6 \%)$ mengalami disfungsi seksual, dimana tingkat pendidikan, jumlah anak, penghasilan perbulan, pekerjaan ibu, dan aktifitas seksual berhubungan dengan disfungsi seksual secara signifikan. Sementara faktor usia, lama pernikahan, dan jenis kontrasepsi tidak berhubungan secara signifikan (Gultom et al., 2018).

Tujuan penelitian ini adalah untuk mengetahui gambaran fungsi seksual wanita yang telah menikah di Kota Makassar.

\section{METODE}

\section{Desain, tempat dan waktu}

Penelitian ini adalah penelitian desktiptif dengan pendekatan cross sectional. Penelitian dilaksanakan di wilayah kerja Puskesmas Bara-Baraya, Puskesmas Jumpandang Baru, dan Puskesmas Tamalanrea pada tahun 2015.

\section{Jumlah dan cara pengambilan subjek}

Populasi pada penelitian ini adalah wanita yang telah menikah di Kota Makassar. Subjek berjumlah 50 orang yang diambil melalui teknik consecutive sampling, yaitu teknik pemilihan sampel yang memenuhi kriteria penelitian sampai jumlah sampel terpenuhi. Adapun kriteria sampel pada penelitian ini yaitu tinggal bersama suami, berumur 20-35 tahun, tidak menderita penyakit kronis, tidak pernah menjalani operasi daerah panggul, tidak merokok, tidak minum alkohol, dan tidak mengkonsumsi obat-obatan berbahaya (narkoba). Pengumpulan data menggunakan kuesioner fungsi seksual wanita (Female Sexual Function Index / FSFI). Analisis yang digunakan adalah analisis univariat untuk menggambarkan fungsi seksual berdasarkan karakteristik subjek penelitian. Data disajikan dalam bentuk tabel distribusi frekuensi.

\section{Jenis dan Cara Pengumpulan Data}

Sumber data penelitian adalah data primer. Peneliti melakukan wawancara pada subjek menggunakan kuesioner fungsi seksual wanita (Female Sexual Function Index / FSFI) untuk memperoleh jawaban dari setiap pertanyaan yang terdapat pada kuesioner FSFI. Kuesioner ini digunakan untuk mengukur fungsi seksual dalam empat minggu terakhir dan terdiri dari enam domain, yaitu hasrat seksual (desire), rangsangan seksual (arousal), lubrikasi (lubrication), orgasme (orgasm), kepuasan (satisfaction), dan rasa nyeri (pain) yang tersebar dalam 19 pertanyaan.

Nilai dari tiap domain dijumlahkan untuk mendapatkan total nilai (full scale score). Total nilai kemudian dikategorikan sebagai disfungsi seksual jika total nilai $\leq$ 26,5 dan dikategorikan normal jika total nilai $>26,5$.

\section{Pengolahan dan analisis data}

Analisis data yang digunakan adalah analisis univariat, bertujuan untuk melihat distribusi frekuensi fungsi seksual berdasarkan karakteristik subjek penelitian.

\section{HASIL}

Hasil dari penelitian ini diketahui bahwa subjek yang mengalami disfungsi seksual sebanyak 26 orang (52\%). Berdasarkan karakteristiknya, subjek yang mengalami disfungsi seksual mayoritas berumur 20-30 tahun yaitu sebanyak 16 orang $(61,5 \%)$, memiliki pendidikan SMA sebanyak 11 orang $(47,3 \%)$, pekerjaan sebagai ibu rumah tangga sebanyak 21 orang $(80,7 \%)$, memiliki anak 2 orang sebanyak 14 orang $(53,8 \%)$, menggunakan kontrasepsi hormonal sebanyak 16 orang 
(61,5\%), dan yang telah menikah selama 3 tahun sebanyak 20 orang (77\%).

\section{PEMBAHASAN}

Penelitian ini menunjukkan bahwa terdapat 26 orang (52\%) subjek yang mengalami disfungsi seksual. Angka ini masih lebih rendah dibandingkan dengan penelitian yang dilakukan oleh Masri dan Sutyarso (2013), dimana jumlah responden wanita yang mengalami disfungsi seksual sebesar 71,4\%. Menurut Krohmer (2004) dalam Windhu (2009), terdapat 39\% dari wanita yang aktif secara seksual mengalami problem dengan aktivitas seksualnya.

Disfungsi seksual adalah gangguan siklus respons seksual atau rasa nyeri saat melakukan hubungan seksual (Sadock, 2014). Siklus respons seksual yang normal merupakan suatu rangkaian proses, yang dialami oleh setiap orang, baik wanita maupun laki-laki pada saat melakukan hubungan seksual dengan pasangannya (Elvira, 2006). Hasil penelitian menunjukkan bahwa skor rata-rata dari setiap domain tidak berada pada skor maksimal yaitu angka 6, dimana skor domain hasrat (desire) 3,6; rangsangan (arousal) 4,08; lubrikasi (lubrication) 4,6; orgasme (orgasm) 4,8; kepuasan (satifaction) 5,2; dan rasa nyeri (pain) 4,3. Kategori utama disfungsi seksual pada wanita yang tercantum dalam edisi revisi keempat Diagnostic and Statistical Manual of Mental Disorder (DSM-IV-TR), yaitu gangguan hasrat seksual, gangguan perangsangan seksual, gangguan orgasme, dan gangguan nyeri seksual (Sadock, 2014).

Hasrat seksual bergantung pada beberapa faktor: dorongan biologis, harga diri yang adekuat, kemampuan menerima seseorang sebagai makhluk seksual, pengalaman yang baik mengenai seks, keberadaan pasangan yang sesuai, dan hubungan baik dalam area nonseksual dengan pasangan. Kerusakan atau tidak adanya faktor ini dapat mengakibatkan menurunnya hasrat.

Faktor psikologis seperti ansietas, rasa bersalah, rasa takut dikaitkan dengan gangguan rangsangan seksual pada wanita. Perubahan kadar testosteron, estrogen, prolaktin, dan tiroksin berhubungan dengan gangguan rangsangan seksual. Demikian juga dengan obat-obatan dengan sifat antihistamin atau antikolinergik dapat menyebabkan berkurangnya lubrikasi vagina.

Berbagai faktor psikologis dikaitkan dengan gangguan orgasme yaitu rasa takut hamil, penolakan oleh pasangan seks, kerusakan vagina, permusuhan terhadap laki-laki, dan rasa bersalah mengenai impuls seksual. Beberapa wanita menganggap orgasme sebagai hilangnya kendali, impuls agresif, merusak, atau kekerasan sehingga rasa takut terhadap impuls ini diekspresikan melalui penghambatan gairah atau orgasme.

Dispareunia adalah nyeri genital sebelum, selama, atau setelah hubungan seks, sering terjadi bersama dengan vaginismus. Episode vaginismus berulang dapat menimbulkan dispareunia dan juga sebaliknya. Sebagian besar penyebabnya adalah faktor dinamik: nyeri pelvis kronis dengan riwayat perkosaan atau penyiksaan seksual masa kanak-kanak, ketegangan / ansietas mengenai kegiatan seksual yang menyebabkan perempuan secara tidak disadari spontan mengontraksikan otot-otot vaginanya. Disamping itu perkosaan dapat menimbulkan dampak psikologi mendalam bagi korban berupa trauma mental, rasa malu, ketakutan, kecemasan sampai keinginan untuk bunuh diri (Paramastri, 2010 dalam Nurbaya \& Qasim, 2018).

Penelitian yang dilakukan oleh Angelina (2010) terhadap wanita usia 26-30 tahun diperoleh prevalensi disfungsi seksual sebesar 15,2\% dengan domain disfungsi seksual yang terbanyak adalah gangguan dorongan dan nyeri seksual. Pada penelitian ini diketahui bahwa subjek yang menggunakan kontrasepsi hormonal lebih banyak mengalami disfungsi seksual $(61,5 \%)$.

Hasil serupa juga didapatkan pada penelitian yang dilakukan oleh Ningsi (2012) dimana penggunaan KB hormonal suntik DMPA (Depo Medroxy Progesterone Acetate) mempengaruhi kejadian disfungsi seksual pada akseptor. Risiko disfungsi seksual berbanding lurus dengan lamanya

Vol. XIV No. 2, Desember 2019 
pemakaian suntikan DMPA (Batlajery $\mathrm{J}$ et al., 2015). Kadar testosteron total jumlahnya rendah pada akseptor pil KB kombinasi yang mengalami disfungsi seksual (Amra et al., 2013).

Demikian pula studi terhadap 32 pasangan suami isteri di kota Makassar menunjukkan bahwa penggunaan kontrasepsi hormonal sangat berdampak pada frekuensi dan durasi hubungan seksual, tetapi tidak mempengaruhi cepat atau lambatnya orgasme yang lebih dipengaruhi karena faktor aktifitas, kelelahan dan ketakutan akan memiliki anak lagi (Irmawati et al., 2018). Penggunaan metode kontrasepsi hormonal dapat menimbulkan gangguan seksual seperti gangguan hasrat, gangguan hormonal, dan gangguan birahi pada wanita (Zettira \& Nisa, 2015).

Pada umumnya zat yang meningkatkan kadar dopamin di dalam otak meningkatkan hasrat, sedangkan zat yang memperkuat serotonin menurunkan hasrat seksual. Testosteron meningkatkan libido pada laki-laki dan wanita, meskipun estrogen menjadi faktor utama lubrikasi yang terlibat di dalam perangsangan wanita dan dapat meningkatkan sensitivitas pada wanita untuk dirangsang. Progesteron sedikit menurunkan hasrat pada laki-laki dan wanita seperti halnya prolactin dan kortisol yang berlebihan (Sadock, 2014).

Pada penelitian ini wanita yang telah menikah selama 3 tahun lebih banyak yang mengalami disfungsi seksual (77\%) dibandingkan yang baru menikah 1-2 tahun. Hal ini dimungkinkan karna faktor risiko terjadinya disfungsi seksual pada wanita multi faktor, diantaranya adalah faktor psikologik. Studi yang dilakukan oleh Masri \& Sutyarso (2013) mengenai stres dan disfungsi seksual terhadap wanita pasangan usia subur di Bandar Lampung menunjukkan ada hubungan yang signifikan antara stres dengan disfungsi seksual. Stres dapat dialami oleh semua wanita, baik yang bekerja diluar rumah maupun tidak. Tekanan dalam menghadapi problem rumah tangga, kekhawatiran berlebihan tentang suami dan anak-anak, kekhawatiran finansial, problem komunikasi suami istri, problem dalam keluarga besar, adalah beberapa jenis problem yang dapat menjadi sumber stres. Stres membuat seseorang menjadi terganggu dan tidak dapat melakukan fungsi sosial, pekerjaan dan fungsi kehidupan yang lain termasuk fungsi seksual (Sadock, 2014).

\section{KESIMPULAN}

Kesimpulan dari penelitian ini adalah jumlah wanita yang telah menikah dan mengalami disfungsi seksual di Kota Makassar sebanyak 26 orang (52\%). Subjek yang mengalami disfungsi seksual mayoritas pada kelompok umur 20-30 tahun $(61,5 \%)$, pendidikan SMA $(42,3 \%)$, memiliki pekerjaan sebagai ibu rumah tangga $(80,7 \%)$, memiliki anak 2 orang $(53,8 \%)$, menggunakan kontrasepsi hormonal $(61,5 \%)$, dan telah menikah selama 3 tahun $(77 \%)$.

\section{SARAN}

Saran bagi wanita yang telah menikah agar menjalin komunikasi yang baik dengan suami termasuk mengkomunikasikan aktifitas seksual mereka dan mengurangi dampak dari stres dengan melakukan rekreasi bersama keluarga diakhir pekan. Bagi peneliti selanjutnya, agar melakukan penelitian pada sampel yang lebih besar serta mengukur kadar hormonal subjek penelitian.

\section{UCAPAN TERIMA KASIH}

Peneliti mengucapkan terimakasih kepada PT. ANTAM Tbk. atas bantuan dana yang diberikan sehingga penelitian ini dapat terlaksana sesuai waktu yang direncanakan.

\section{DAFTAR PUSTAKA}

Amra Y, Josephine L.T and Hartono E. 2013. Hubungan Kadar Testosteron Total Dengan Fungsi Seksual Wanita Pada Akseptor Pil Kb Kombinasi. Jurnal Program Pascasarjana Universitas Hasanuddin.

Angelina. 2010. Prevalence of Sexual Dysfunction Based on Female Sexual Function Index and 
Perception of Newly Bride in Jati Village and Its Related Factors. Indonesian Journal of Obstetrics and Gynecologi, Vol. 34 (4).

Batlajery J, Hamidah and Mardiana. 2015. Penggunaan Metode Kontrasepsi Suntikan DMPA Berhubungan dengan Disfungsi Seksual Wanita Pada Akseptor KB Suntik. Jurnal IImu dan Teknologi Kesehatan, vol. 2 (3) 49-56.

Elvira S.D. 2006. Disfungsi Seksual Pada Perempuan. Jakarta: BP-FKUI.

Gultom G.I., Sutyarso and Salfarina F. 2018. Perbedaan Fungsi Seksual Wanita Perkotaan dan Pedesaan di Kecamatan Kedaton dan Kecamatan Pagelaran. Majority, vol. 7 (2): 14-23.

Irmawati, Multazam A and Fachrin S.A. 2018. Metode Kontrasepsi dan Aktifitas Seksual Pasangan Suami Istri di Kota Makassar Tahun 2017. Patria Artha Journal of Nursing Science, Vo. 2 (2) 109-118.

Masri C.S and Sutyarso. 2014 Hubungan Stres Menurut Skala Social Readjustment Rating Scale Dengan Kejadian Disfungsi Seksual Pada Wanita Pasangan Usia Subur di Puskesmas Kota Karang Teluk Betung Bandar Lampung. Medical Journal Of Lampung University, 3 (1) 46-53.

Maulana R and Masang. 2012. Penyebab Konflik Dalam Keluarga. (Online). (http://log.viva.co.id, diakses 17 April 2015)

McCabe M.P., Sharlip I.D., Lewis R., Atalla E., Balon R., Fisher A.D., Laumann E., Lee S.W and Segraves R.T. 2016. Risk Factors for Sexual Dysfunction Among Woman and Mens: A Concensus Statement From the Fourth International Consultation on Sexual Medicine. J. Sex. Med. 13: 153-167.

Ningsi A. 2012. Pengaruh Penggunaan Metode Kontrasepsi Suntikan DMPA Terhadap Kejadian Disfungsi Seksual. Jurnal Program Pascasarjana Universitas Hasanuddin, Vol. 2 (1): 36-47.

Nurbaya S and Qasim M. 2018. Penerapan Pendidikan Seks (Underwear Rules) Terhadap Pencegahan Kekerasan Seksual Pada Anak dan Orang Tua di SD Negeri 52 Welonge Kabupaten Soppeng. Jurnal Media Kesehatan Politeknik Kesehatan Makassar, vol. 13 (2) 19-27.

Rizvi S.J., Yeung N.W and Kennedy S.H. 2011. Instruments to Measure Sexual Dysfunction in Community and Psychiatric Population. Journal of Psychosomatic Research, 70 99109.

Sadock. 2014. Buku Ajar Psikiatri Klinis. Edisi 2. EGC: Jakarta.

Weinberger J.M., Houman J., Caron A.T. and Anger J. 2018. Female Sexual Dysfunction: A Systematic Review of Outcomes A cross Various Treatment Modalities. Sex. Med. Rev. 1-28.

Windhu S.C. 2009. Disfungsi Seksual. Yogyakarta: ANDI Offset

Zettira Z and Nisa K. 2015. Analisis Hubungan Penggunaan Kontrasepsi Hormonal Dengan Disfungsi Seksual Pada Wanita. Majority, Vol. 4 (7): 103-107.

Zhang C., Tang J., Zhu L., Zhang L., Xu T., Lang $J$ and Xie Y. 2017. A Population-Based Epidemiologic Study of Female Sexual Dysfunction Risk in Mainland China: Prevalence and Predictors. Journal Sex Med, 14: 1348-1356. 
Tabel 1

Karakteristik Subjek Pada Penelitian Fungsi Seksual Wanita Yang Telah Menikah di Kota Makassar

\begin{tabular}{|c|c|c|}
\hline \multirow[t]{2}{*}{ Karakteristik Subjek } & \multicolumn{2}{|c|}{ Jumlah } \\
\hline & $\mathrm{n}$ & $\%$ \\
\hline \multicolumn{3}{|l|}{ Umur (Tahun) } \\
\hline $20-30$ & 37 & 74 \\
\hline $31-35$ & 13 & 26 \\
\hline \multicolumn{3}{|l|}{ Pendidikan } \\
\hline SD & 6 & 12 \\
\hline SMP & 8 & 16 \\
\hline SMA & 28 & 56 \\
\hline Sarjana & 8 & 16 \\
\hline \multicolumn{3}{|l|}{ Pekerjaan } \\
\hline IRTं & 44 & 88 \\
\hline Karyawan Swasta & 3 & 6 \\
\hline PNS & 3 & 6 \\
\hline \multicolumn{3}{|l|}{ Jumlah Anak } \\
\hline Tidak ada & 2 & 4 \\
\hline 1 orang & 21 & 42 \\
\hline 2 orang & 27 & 54 \\
\hline \multicolumn{3}{|l|}{ Jenis Kontrasepsi } \\
\hline Tidak ber-KB & 18 & 36 \\
\hline Non Hormonal & 2 & 4 \\
\hline Hormonal & 30 & 60 \\
\hline \multicolumn{3}{|l|}{ Lama Menikah } \\
\hline 1 tahun & 3 & 6 \\
\hline 2 tahun & 6 & 12 \\
\hline 3 tahun & 41 & 82 \\
\hline Total & 50 & 100 \\
\hline
\end{tabular}

Vol. XIV No. 2, Desember 2019

DOI: https://doi.org/10.32382/medkes.v14i2.1227 
Tabel 2

Fungsi Seksual Wanita Yang Telah Menikah di Kota Makassar Berdasarkan Karakteristik

\begin{tabular}{|c|c|c|c|c|c|c|}
\hline \multirow[t]{3}{*}{ Karakteristik Subjek } & \multicolumn{4}{|c|}{ Fungsi Seksual } & \multicolumn{2}{|c|}{ Total } \\
\hline & \multicolumn{2}{|c|}{ Disfungsi } & \multicolumn{2}{|c|}{ Normal } & \multirow[b]{2}{*}{$\mathrm{n}$} & \multirow[b]{2}{*}{$\%$} \\
\hline & $\mathrm{n}$ & $\%$ & $\mathrm{n}$ & $\%$ & & \\
\hline \multicolumn{7}{|l|}{ Umur (Tahun) } \\
\hline $20-30$ & 16 & 61,5 & 21 & 87,5 & 37 & 74 \\
\hline $31-35$ & 10 & 38,5 & 3 & 12,5 & 13 & 26 \\
\hline \multicolumn{7}{|l|}{ Pendidikan } \\
\hline SD & 5 & 19,2 & 1 & 4,2 & 6 & 12 \\
\hline SMP & 5 & 19,2 & 3 & 12,5 & 8 & 16 \\
\hline SMA & 11 & 42,3 & 17 & 70,8 & 28 & 56 \\
\hline Sarjana & 5 & 19,2 & 3 & 12,5 & 8 & 16 \\
\hline \multicolumn{7}{|l|}{ Pekerjaan } \\
\hline $\mathrm{IRT}$ & 21 & 80,7 & 23 & 95,8 & 44 & 88 \\
\hline Swasta & 3 & 11,5 & 0 & 0 & 3 & 6 \\
\hline PNS & 2 & 0,8 & 1 & 4,2 & 3 & 6 \\
\hline \multicolumn{7}{|l|}{ Jumlah Anak } \\
\hline Tidak Ada & 2 & 0,8 & 0 & 0 & 2 & 4 \\
\hline 1 orang & 10 & 38,5 & 11 & 45,8 & 21 & 42 \\
\hline 2 orang & 14 & 53,8 & 13 & 54,2 & 27 & 54 \\
\hline \multicolumn{7}{|l|}{ Status Kontrasepsi } \\
\hline Tidak ber-KB & 10 & 38,5 & 8 & 33,3 & 18 & 36 \\
\hline Non Hormonal & 0 & 0 & 2 & 8,3 & 2 & 4 \\
\hline Hormonal & 16 & 61,5 & 14 & 58,3 & 30 & 60 \\
\hline \multicolumn{7}{|l|}{ Lama Menikah } \\
\hline 1 Tahun & 3 & 11,5 & 0 & 0 & 3 & 6 \\
\hline 2 Tahun & 3 & 11,5 & 3 & 12,5 & 6 & 12 \\
\hline 3 Tahun & 20 & 77 & 21 & 87,5 & 41 & 82 \\
\hline TOTAL & 26 & 52 & 24 & 48 & 50 & 100 \\
\hline
\end{tabular}

Vol. XIV No. 2, Desember 2019

DOI: https://doi.org/10.32382/medkes.v14i2.1227 